\title{
A Combination of Wheat Bran and Vegetable Oils as Feedstuff in Laying Hens' Diet: Impact on Egg Quality Parameters
}

\author{
Elisa Wanzenböck ${ }^{1}$, Matthias Schreiner ${ }^{1}$, Ulrike Zitz ${ }^{1}$, Birgit Bleich ${ }^{1}$, Sophie Figl2 \\ Wolfgang Kneifel ${ }^{1}$, Karl Schedle ${ }^{2}$ \\ ${ }^{1}$ Institute of Food Science, University of Natural Resources and Life Sciences Vienna, Vienna, Austria \\ ${ }^{2}$ Institute of Animal Nutrition, Livestock Products, and Nutrition Physiology, University of Natural Resources and Life Sciences \\ Vienna, Vienna, Austria \\ Email: *elisa.wanzenboeck@boku.ac.at
}

How to cite this paper: Wanzenböck, E., Schreiner, M., Zitz, U., Bleich, B., Figl, S., Kneifel, W. and Schedle, K. (2018) A Combination of Wheat Bran and Vegetable Oils as Feedstuff in Laying Hens' Diet: Impact on Egg Quality Parameters. Agricultural Sciences, 9, 676-691.

https://doi.org/10.4236/as.2018.96047

Received: April 16, 2018

Accepted: June 18, 2018

Published: June 21, 2018

Copyright $\odot 2018$ by authors and Scientific Research Publishing Inc. This work is licensed under the Creative Commons Attribution International License (CC BY 4.0).

http://creativecommons.org/licenses/by/4.0/

c) (i) Open Access

\begin{abstract}
Wheat bran (WB) is an important side product of the milling industry and plays an increasing role in animal feeding. Despite its nutritional value, its application is limited as a result of its pronounced fiber content. Taking into account the potential use of WB supplementation in feed for laying hens thereby replacing human edible foodstuffs, the influence of different WB levels $(0$ $\mathrm{g} \cdot \mathrm{kg}^{-1}, 75 \mathrm{~g} \cdot \mathrm{kg}^{-1}$, and $150 \mathrm{~g} \cdot \mathrm{kg}^{-1}$ ) combined with sunflower or rapeseed oil on egg quality was studied. Among the egg-related quality parameters investigated, eggshell cleanliness, shell rigidity, egg weight, haugh units, yolk and albumen mass, color, $\mathrm{pH}$ value, dry matter, crude protein, crude ash, fatty acid spectrum, cholesterol and $\alpha$-tocopherol of the yolk were monitored. No negative effect of WB supplementation was observed in terms of egg weight, shell weight, albumen weight, yolk weight, haugh unit, shell thickness and eggshell breaking strength. However, certain parameters (i.e. $\alpha$-tocopherol content, $\Sigma \mathrm{n}-3$ PUFA) were enhanced by feeding $75 \mathrm{~g} \cdot \mathrm{kg}^{-1}$ and $150 \mathrm{~g} \cdot \mathrm{kg}^{-1} \mathrm{WB}$. The use of WB (75 g. $\mathrm{kg}^{-1}$ and $150 \mathrm{~g} \cdot \mathrm{kg}^{-1}$ ) had no negative effect on egg quality and can, therefore, be recommended for laying hen diets up to $150 \mathrm{~g} \cdot \mathrm{kg}^{-1}$. Additionally, the application of rapeseed oil high in $\Sigma \mathrm{n}-3$ PUFA resulted in yolks exhibiting a low $\Sigma$ n-6 PUFA/ $\Sigma$ n-3 PUFA ratio.
\end{abstract}

\section{Keywords}

Laying Hens, Wheat Bran, Vegetable Oils, Egg Quality, Fatty Acid Profile

\section{Introduction}

Taking into account that the increasing competition between humans and lives- 
tock animals regarding the utilization of grains as a food or a feed resource is a rising problem, the use of valorized side-streams accumulating in the food industry as feedstuffs comprises a future-oriented and sustainable approach for an economically and ecologically practicable handling of resources. In this context, wheat bran (WB), a by-product of the milling industry with an annual production amount of 150 million tons worldwide, has become of major relevance. Owing to its nutritionally valuable compounds, WB is currently regarded as a low-cost feed compound conferring dietary fiber [1]. Usually, feedstuffs high in dietary fiber are directly correlated with low energy and nutrient content [2]. Nevertheless, WB contains valuable ingredients like protein, starch, lipids, and minerals as well as minor components like organic acids, $\beta$-glucan, phenolic compounds, tocopherols, thiamine and folate [1] [3]. Related to these nutritive features and also due to the volatile prices of feed ingredients, the application of fiber-rich by-products has received increasing attention in the poultry industry. Presupposed that poultry receives an isonitrogenous and isoenergetic diet, literature reports about an inclusion rate reach up to $50 \mathrm{~g} \cdot \mathrm{kg}^{-1}$ of WB in a laying hens' diet [4].

However, to overcome the lack of energy caused by such a wheat bran supplementation, it is inevitable to implement elevated levels of oil in the diet. For this purpose, sunflower oil and rapeseed oil seem to be useful sources.

Depending on the diet egg yolks may display variable profiles of nutritionally valuable fatty acids. The quality of the fat is mostly determined by the ratio of nn-6 PUFA/ $\sum n-3$ PUFA [5]. It is well known that docosahexaenoic acid (DHA) bears some beneficial health benefits for humans. Docosahexaenoic acid represents at least $0.5 \%$ of the total amount of fatty acids in the yolk and can be increased by $2.5 \%-3.0 \%$ through a dietary supplementation of omega-3 long-chain polyunsaturated fatty acids or alpha-linolenic acid containing oils [6]. Laying hens possess a well-developed enzymatic system to incorporate long-chain $\Sigma \mathrm{n}-3$ PUFA in the yolk by converting it from alpha-linolenic acid (C18:3n-3) provided by their feed [7]. For this reason, it seems to be beneficial to incorporate such PUFA in the egg yolk, by a dietary supplementation of alpha-linolenic acid.

Several positive effects of wheat bran as animal feed have been well-documented [2] [8] [9], but in case of a sustainable utilization of by-products from the food industry in animal feeding concepts, a more detailed look into the subject of including WB in laying hens' diet is warranted [10]. For this purpose, the present study was carried out to investigate the influence of high fiber feeding regimes using WB at two selected levels and in combination with sunflower and rapeseed oil supplementation as available cost-efficient vegetable oils on the egg yolk fatty acid profile, tocopherol and cholesterol content as well as the external egg quality. To our knowledge, hitherto there is no other study dedicated to the inclusion of WB as a sole fiber source up to a level of $150 \mathrm{~g}^{\mathrm{kg}} \mathrm{gg}^{-1}$ without considering decreased energy contents in the fiber-rich diets. 


\section{Materials and Methods}

\subsection{Diets, Raw Material and Feeding Trial}

The trial was approved by the ethics commission of the Austrian Ministry of Science and Research (BMWF-66.016/0010-WF/V/3b/2016) and of the Austrian Agency for Health. In total, 24 Lohman Brown-Classic laying hens (35 weeks old) with an initial body weight of $2000 \pm 269 \mathrm{~g}$ purchased from a commercial breeder were subjected to this experiment. To minimize the influence of body weight, the individuals were weighed, leg-tagged and distributed to six feeding regimes according to their body weight, randomly. Each hen was accommodated in one metabolism cage equipped with a wooden perch, a drinker and an attached laying nest. The cages enabled controlled feeding and birds were exposed to light for $16 \mathrm{~h}$ per $\mathrm{d}$. Treatments were arranged as a $3 \times 2$ factorial design, with three WB concentrations $\left(0 \mathrm{~g} \cdot \mathrm{kg}^{-1}, 75 \mathrm{~g} \cdot \mathrm{kg}^{-1}\right.$, and $\left.150 \mathrm{~g} \cdot \mathrm{kg}^{-1}\right)$ and two kinds of vegetable oil (rapeseed oil and sunflower oil). The feed intake was limited to $110 \mathrm{~g}$ per $\mathrm{d}$. The hens were fed equal amounts twice daily (8:00 AM and 5:00 PM). Water was provided ad libitum for all treatments and the individual health status of all laying hens was recorded daily. Each of the six treatments was studied with four laying hens. The diets were calculated to reach balanced metabolizable energy (11.4 $\left.\mathrm{AME}_{\mathrm{N}} \mathrm{MJ} \mathrm{ME} / \mathrm{kg}\right)$, crude protein $\left(170 \mathrm{~g} \cdot \mathrm{kg}^{-1}\right)$, and digestible amino acids content (Table 1). Nutrient concentration was calculated to meet or exceed the nutritive requirements for laying hens of the manufacturer (Lohmann, Cuxhaven, Germany).

Table 1. General composition of the different diets administered in this study.

\begin{tabular}{|c|c|c|c|c|c|c|}
\hline \multirow{2}{*}{ Ingredients $\left[\mathrm{g} \cdot \mathrm{kg}^{-1}\right]$} & \multicolumn{6}{|c|}{ Feed $^{1}$} \\
\hline & CON R & CON S & LOW R & LOW S & HIGH R & HIGH S \\
\hline Corn & 597 & 597 & 517 & 517 & 435 & 435 \\
\hline Wheat bran & - & - & 75 & 75 & 150 & 150 \\
\hline Soybean meal without hulls & 269 & 269 & 258 & 258 & 248 & 248 \\
\hline Rapeseed oil & 29 & - & 45 & - & 62 & - \\
\hline Sunflower oil & - & 29 & - & 45 & - & 62 \\
\hline Oyster shells & 57 & 57 & 57 & 57 & 58 & 58 \\
\hline Limestone & 28 & 28 & 29 & 29 & 29 & 29 \\
\hline $\mathrm{CaPO}^{4}$ & 13 & 13 & 12 & 12 & 11 & 11 \\
\hline $\mathrm{NaCl}$ & 4 & 4 & 4 & 4 & 4 & 4 \\
\hline Methionine & 1 & 1 & 11 & 11 & 12 & 12 \\
\hline Vitamin premix ${ }^{2}$ & 0.25 & 0.25 & 0.25 & 0.25 & 0.25 & 0.25 \\
\hline Trace element premix ${ }^{3}$ & 0.56 & 0.56 & 0.56 & 0.56 & 0.56 & 0.56 \\
\hline Cholin-Cl & 0.80 & 0.80 & 0.80 & 0.80 & 0.80 & 0.80 \\
\hline Phytase $^{4}$ & 0.15 & 0.15 & 0.15 & 0.15 & 0.15 & 0.15 \\
\hline NSP-Enzyme ${ }^{5}$ & 0.05 & 0.05 & 0.05 & 0.05 & 0.05 & 0.05 \\
\hline
\end{tabular}

${ }^{1} \mathrm{CON} \mathrm{R}=0 \mathrm{~g} \cdot \mathrm{kg}^{-1}$ wheat bran, rapeseed oil; CON S $=0 \mathrm{~g} \cdot \mathrm{kg}^{-1}$ wheat bran, sunflower oil; LOW R $=75 \mathrm{~g} \cdot \mathrm{kg}^{-1}$ wheat bran, rapeseed oil; LOW S $=75 \mathrm{~g} \cdot \mathrm{kg}^{-1}$ wheat bran, sunflower oil; HIGH R $=150 \mathrm{~g} \cdot \mathrm{kg}^{-1}$ wheat bran, rapeseed oil; HIGH S $=150 \mathrm{~g} \cdot \mathrm{kg}^{-1}$ wheat bran, sunflower oil; ${ }^{2}$ Vitamins per kg premix: $4 \times 10^{7} \mathrm{IU}$ vitamin A, $1.7 \times 10^{7} \mathrm{IU}$ vitamin D3, $1.7 \times 10^{5} \mathrm{mg}$ vitamin $\mathrm{E}, 1.4 \times 10^{4} \mathrm{mg}$ vitamin $\mathrm{K}, 1 \times 10^{5} \mathrm{mg}$ vitamin $\mathrm{B} 1,2.5 \times$ $10^{4} \mathrm{mg}$ vitamin B2, $1.5 \times 10^{4} \mathrm{mg}$ vitamin B6, $75 \mathrm{mg}$ vitamin B12, $2.3 \times 10^{5} \mathrm{mg}$ nicotinic acid, $65 \mathrm{mg}$ pantothenic acid, $6.500 \mathrm{mg}$ folic acid and $400 \mathrm{mg}$ biotin. ${ }^{3}$ Trace elements per kg premix: $120 \mathrm{~g} \mathrm{Fe}, 120 \mathrm{~g} \mathrm{Zn}, 180 \mathrm{~g}$ $\mathrm{Mn}, 30 \mathrm{~g} \mathrm{Cu}, 2 \mathrm{~g} \mathrm{I}, 2 \mathrm{~g}$ Co and $0.8 \mathrm{~g}$ Se. ${ }^{4} \mathrm{ZY}$-Phytase ${ }^{\oplus} ;{ }^{5}$ Rovabio ${ }^{\circ}$. 


\subsection{Sample Collection and Procedures}

The experiment lasted for $21 \mathrm{ds}$. After an adaption phase of $15 \mathrm{ds}$, eggs were individually collected from each animal, weighed and subjected to further analyses.

Collected eggs $(n=144)$ were inspected for visible $\operatorname{dirt}(0=$ no dirt, $1=\bmod$ erate dirt, 2 = severe dirt), and monitored regarding egg weight and shell strength using a texture analyzer (TA.HD.plus Texture analyzer, Hamilton, USA). Afterwards, eggs were broken and yolk and albumen weight determined. Yolk color $\left(\mathrm{L}^{*}, \mathrm{a}^{*}, \mathrm{~b}^{\star}\right)$ was measured using a reflectance colorimetry spectro-photometer (CM-600d; Konica Minolta, Tokyo). Haugh units were calculated according to the formula $\mathrm{HU}=100 \times \log \left(\mathrm{H}+7.57-1.7 \mathrm{~W}^{0.37}\right)$. The height of the albumen was denoted as $\mathrm{H}$, while $\mathrm{W}$ was the weight of the egg [11]. Shell weight and thickness (including shell membrane) were registered after rinsing under tap running water and drying overnight at $103^{\circ} \mathrm{C}$. Shell thickness was determined on two randomized points on the poles of the eggshell. Subsequently, three yolks of the same animal were pooled (collected at ds $16-18$ and $19-21$ ), respectively. Pooled and homogenized yolks were freeze-dried overnight using an Edwards Modulyo 4K freeze drier (Edwards, Kniese and Co., Marburg, Germany). Dry matter was determined by back-weighing the lyophilisate. The dried yolk was manually powdered in a stone mortar and stored at $-80^{\circ} \mathrm{C}$ for further analyses. Representative samples of diets, taken at the beginning of the feeding trial from all tested diets, were ground in a Retsch ultra-centrifugal mill of type ZM1 (Haan, Germany) with a $1 \mathrm{~mm}$ sieve. Regarding the dry matter, ash, crude protein (CP) and ether extract (EE) all samples of eggs and feed were analyzed in duplicates according to the official methods of VDLUFA [12]. Additionally, samples of feed underwent starch, sugar and neutral detergent fiber (NDF) analyses according to Naumann and Bassler [12]. Phytic acid was determined according to Makkar et al. [13], and gross energy in a bomb calorimeter under oxygen conditions (IKA-Kalorimeter C400, Bartelt, Graz, Austria). Calcium, sodium, and zinc were analyzed by means of atomic absorption spectrophotometry (AAnalyst 200, Perkin Elmer, Brunn am Gebirge, Austria). After the previous wet-ashing in a microwave oven (MLS-ETHOS plus Terminal 320, Leutkirch, Germany), phosphorus was determined using the vanado-molybdate method [12] based on absorption measurement at $436 \mathrm{~nm}$

(U5100-Spectrophotometer-Hitatchi, Metrohm, Wien, Austria).

\subsection{Fatty Acid and Cholesterol Levels}

Pooled yolk samples and corresponding feed samples were analyzed according to the method of Schreiner [14]. In brief, fatty acid methyl esters (FAME) were obtained from freeze-dried samples by a combined extraction/tramsmethylation. An amount of $50 \mathrm{mg}$ yolk powder was weighed into a $15 \mathrm{ml}$ reaction tube and 2 $\mathrm{mL}$ of toluene containing $1 \mathrm{mg} / \mathrm{ml}$ of each internal standard (C17 methyl ester and alpha -cholestane) was added. For transmethylation, $3 \mathrm{ml}$ of methanolic $\mathrm{HCl}, 5 \%(\mathrm{v} / \mathrm{v})$ were supplemented and samples were placed in a $70^{\circ} \mathrm{C}$ water bath 
for two hours with occasional shaking by hand. After transmethylation, $5 \mathrm{~mL}$ of $6 \%$ calcium carbonate were added and the mixture was centrifuged gently for 5 mins in order to obtain phase separation. The upper phase was transferred to another reaction tube where the solvent was removed by a stream of N2. To the dry sample, $100 \mu \mathrm{l}$ BSTFA/TMCS and $100 \mu \mathrm{l}$ pyridine were added for masking the hydroxyl group of cholesterol. Derivatization was obtained at $60^{\circ} \mathrm{C}$ in a drying oven for 30 mins. After reaction, the samples were dissolved in $2 \mathrm{~mL}$ toluene. Gas chromatography was performed on a Thermo scientific Trace GC Ultra system (Waltham, USA) using a RTX-225 capillary column (30 m lengh; $0.25 \mathrm{~mm}$ ID). Restekcorp 800-356-1688 Hydrogen was used as carrier gas at a flow rate of $3 \mathrm{ml} / \mathrm{min}$ and a head pressure of $90 \mathrm{kPa}$. Detection was performed via an autosampler and the temperature program was $120^{\circ} \mathrm{C}$ for one min followed by a $20^{\circ} \mathrm{C} / \mathrm{min}$ ramp to 170 and continuing with a $2.5^{\circ} \mathrm{C} / \mathrm{min} \mathrm{ramp}$ to 220 . This final temperature was constant for one min. Fatty acid methyl ester were determined by comparison with appropriate standards and no response factors were used for calculation.

\section{4. $\alpha$-Tocopherol}

Alpha-Tocopherol analyses in pooled yolk and diet samples were performed according to Panfili et al. [15] with minor modifications. For saponification, 500 $\mathrm{mg}$ of freeze-dried yolk powder or $1000 \mathrm{mg}$ of feed samples were placed in a reaction vial and $2 \mathrm{ml}$ of potassium hydroxide $(600 \mathrm{~g} / \mathrm{l}), 2 \mathrm{ml}$ ethanol (95\%), 2 $\mathrm{ml}$ of sodium chloride $(10 \mathrm{~g} / \mathrm{l})$, and $5 \mathrm{ml}$ of ethanolic pyrogallol $(60 \mathrm{~g} / \mathrm{l})$ added. Subsequently, after $45 \mathrm{~min}$ of saponification at $70^{\circ} \mathrm{C}$, tubes were cooled in an ice bath, $15 \mathrm{ml}$ of sodium chloride $(10 \mathrm{~g} / \mathrm{l})$ was added and followed by extraction with $15 \mathrm{ml}$ of $\mathrm{n}$-hexane/ethyl acetate $(9: 1 \mathrm{v} / \mathrm{v})$. This procedure was conducted twice and the organic layer was recollected and evaporated to dryness. To dissolve the residue, $2 \mathrm{ml}$ of $\mathrm{n}$-hexane were used. Chromatography was performed using an HPLC analytical system (Shimadzu, Kyoto, Japan) equipped with a fluorescence detector (295 nm EM and $354 \mathrm{~nm} \mathrm{EX).} \mathrm{An} \mathrm{amino} \mathrm{phase} \mathrm{column} \mathrm{was}$ used for separation with a mobile phase composed of $70 \%$ n-hexane and $30 \%$ ethylacetate.

\subsection{Detection of Salmonella Spp. on Eggshells}

Intact eggs were aseptically transferred into sterile stomacher bags and treated as described by Musgrove et al. [16]. In detail, one egg was placed per bag and 30 $\mathrm{ml}$ buffered peptone water added. After $5 \mathrm{~min}$ of incubation, the egg was manually rubbed for one min to release the microorganisms adhering to the surface into the liquid phase. After the removal of the egg from the bag under sterile conditions, the solution was mixed thoroughly by stomaching the content for 60 sec. Then $250 \mu \mathrm{l}$ of Salmonella supplement (bioMérieux Ref. 42650) were added and the bag was incubated for $20 \mathrm{~h}$ at $41.5^{\circ} \mathrm{C}$ in order to selectively enrich the microorganisms. 
Following these enrichment procedures, the VIDAS ${ }^{\mathrm{TM}}$ UP Salmonella (SPT) Assay (bioMérieux, Marcy l'Etoile France) was performed, throughout following the manufacturer's instructions. Briefly, $500 \mu \mathrm{l}$ of the enriched solution was applied to the single-dose reagent strip, and each strip was heated at $131^{\circ} \mathrm{C}$ for 5 min using a VIDAS ${ }^{\mathrm{TM}}$ Heat \& Go dry heating system (bioMérieux, Marcy l'Etoile, France). After cooling to room temperature for $10 \mathrm{~min}$, strips were inserted into the mini VIDAS ${ }^{\mathrm{TM}}$ instrument (bioMérieux, Marcy l'Etoile, France), and the detection procedure was initiated. Results were automatically calculated and denoted as negative or positive per $3 \mathrm{~g}$ per eggshell surface.

\subsection{Statistical Analysis}

Data were evaluated with a two-way ANOVA using the MIXED procedure of SAS Enterprise Guide 7.1, according to the following model: xijk $=\mu+\alpha \mathrm{i}+\beta \mathrm{i}+$ $(\alpha \beta) \mathrm{ij}+\mathrm{Ak}+$ eijk, $\mathrm{x}=$ dependent variable, $\mu=$ overall mean, $\alpha=$ effect of WB (0 $\mathrm{g} \cdot \mathrm{kg}^{-1}, 750 \mathrm{~g} \cdot \mathrm{kg}^{-1}$ and $\left.150 \mathrm{~g} \cdot \mathrm{kg}^{-1}\right), \beta=$ effect of oil (rapeseed oil or sunflower oil), $\mathrm{Ak}=$ random effect of animals $(\mathrm{k}=1,2, \ldots, 24)$, eijk = residual experimental error. Multiple comparisons of the means were determined using the Tukey Kramer test. Treatment means were presented as least-squares means, and significant differences in the means are displayed with different superscripts. The influence of the diets on the categorical parameter "dirtiness of eggshells" (D) treated as ordered multinomial response was calculated according to the GLIMMIX procedure (considering the random effect of the individuals) using SAS Enterprise Guide 7.1.

\section{Results and Discussion}

\subsection{Feed Composition}

A detailed description of the chemical composition and the fatty acid profile of the six diets applied in this study are presented in Table 2 and Table 3. Aiming at a theoretically calculated protein concentration of $170 \mathrm{~g} / \mathrm{kg}$, the analyzed crude protein levels were somewhat higher but almost similar, practically ranging between $177 \mathrm{~g} / \mathrm{kg}$ and $182 \mathrm{~g} / \mathrm{kg}$. Upon calculation, the target $\mathrm{AME}_{\mathrm{N}}$ value of 11.4 was slightly lower compared to the analyzed values of the diets containing no bran (CON R: $11.7 \mathrm{MJ} / \mathrm{kg}$; CON S: $11.9 \mathrm{MJ} / \mathrm{kg}$ ) and $75 \mathrm{~g} / \mathrm{kg}$ bran (LOW R: $11.6 \mathrm{MJ} / \mathrm{kg}$; LOW S: $11.7 \mathrm{MJ} / \mathrm{kg}$ ). Due to lower starch and higher neutral detergent fiber (NDF) levels in those diets containing higher amounts of bran, it was necessary to add more oil to meet the energy requirements. Consequently, ether extract (EE) levels increased in parallel with the amount of WB. Correspondingly, higher phytate contents were found owing to higher amounts of WB in the diet, i.e. CON R showed a phytate content of $10.8 \mathrm{~g} / \mathrm{kg}$, whereas HIGH R displayed a level of $11.6 \mathrm{~g} / \mathrm{kg}$. As a logical consequence of the oil supplementation, the amounts of saturated fatty acids (SFA), polyunsaturated fatty acids (PUFA), omega- 6 polyunsaturated acids ( $\sum \mathrm{n}-6$ PUFA) and the percentage distribution between $\Sigma \mathrm{n}-3$ PUFA and $\Sigma \mathrm{n}-6$ PUFA ( $\sum \mathrm{n}-6$ PUFA/ $/ \mathrm{n}-3$ PUFA) were higher in 
Table 2. Analyzed chemical composition in fresh matter of the different diets administered in this study.

\begin{tabular}{ccccccc}
\hline \multirow{2}{*}{ Parameter } & \multicolumn{7}{c}{ Feed $^{1}$} \\
\cline { 2 - 7 } & CON R & CON S & LOW R & LOW S & HIGH R & HIGH S \\
\hline Calculated AME $[\mathrm{N}] / \mathrm{kg}]$ & 11.7 & 11.9 & 11.6 & 11.7 & 11.4 & 11.3 \\
Dry matter $\left[\mathrm{g} \cdot \mathrm{kg}^{-1}\right]$ & 890.9 & 889.4 & 892.5 & 892.7 & 895.8 & 898.8 \\
Crude ash $\left[\mathrm{g} \cdot \mathrm{kg}^{-1}\right]$ & 12.6 & 11.8 & 12.2 & 12.4 & 12.7 & 12.2 \\
Ether extract $\left[\mathrm{g} \cdot \mathrm{kg}^{-1}\right]$ & 4.9 & 5.1 & 6.5 & 6.5 & 8.1 & 8.3 \\
Crude protein $\left[\mathrm{g} \cdot \mathrm{kg}^{-1}\right]$ & 17.7 & 18.2 & 17.9 & 18.1 & 18.0 & 18.1 \\
Starch $\left[\mathrm{g} \cdot \mathrm{kg}^{-1}\right]$ & 42.0 & 42.0 & 37.7 & 38.1 & 32.7 & 32.3 \\
Total ether extract $\left[\mathrm{g} \cdot \mathrm{kg}^{-1}\right]$ & 5.6 & 5.4 & 7.0 & 7.3 & 8.8 & 8.7 \\
Sugar $\left[\mathrm{g} \cdot \mathrm{kg}^{-1}\right]$ & 28.9 & 29.5 & 31.8 & 33.9 & 36.1 & 32.4 \\
Neutral detergent fiber $\left[\mathrm{g} \cdot \mathrm{kg}^{-1}\right]$ & 8.0 & 7.4 & 10.7 & 10.1 & 12.3 & 12.9 \\
Crude fiber $\left[\mathrm{g} \cdot \mathrm{kg}^{-1}\right]$ & 2.0 & 1.9 & 2.8 & 2.7 & 3.1 & 3.1 \\
Zinc $\left[\mu \mathrm{\mu g} \cdot \mathrm{g}^{-1}\right]$ & 104.3 & 108.1 & 104.2 & 108.1 & 101.9 & 104.0 \\
Calcium $\left[\mathrm{g} \cdot \mathrm{kg}^{-1}\right]$ & 30.2 & 29.8 & 33.1 & 31.7 & 33.3 & 30.8 \\
Sodium $\left[\mathrm{g} \cdot \mathrm{kg}^{-1}\right]$ & 2.2 & 2.0 & 2.1 & 2.0 & 2.0 & 2.1 \\
Phosphorus $\left[\mathrm{g} \cdot \mathrm{kg}^{-1}\right]$ & 6.5 & 5.9 & 6.5 & 6.1 & 7.0 & 7.1 \\
Phytic acid $\left[\mathrm{g} \cdot \mathrm{kg}^{-1}\right]$ & 10.8 & 10.7 & 11.1 & 11.2 & 11.6 & 11.7 \\
Gross energy $\left[\mathrm{MJ} / \mathrm{kg}^{-1}\right]$ & 15.7 & 15.5 & 15.9 & 15.9 & 16.3 & 16.3 \\
$\alpha$-Tocopherol $[\mathrm{mg} / 100 \mathrm{~g}]$ & 6.9 & 8.9 & 9.4 & 3.6 & 2.6 & 8.0 \\
\hline
\end{tabular}

${ }^{1} \mathrm{CON} \mathrm{R}=0 \mathrm{~g} \cdot \mathrm{kg}^{-1}$ wheat bran, rapeseed oil; CON S $=0 \mathrm{~g} \cdot \mathrm{kg}^{-1}$ wheat bran, sunflower oil; LOW R $=75 \mathrm{~g} \cdot \mathrm{kg}^{-1}$ wheat bran, rapeseed oil; LOW S $=75 \mathrm{~g} \cdot \mathrm{kg}^{-1}$ wheat bran, sunflower oil; HIGH R $=150 \mathrm{~g} \cdot \mathrm{kg}^{-1}$ wheat bran, rapeseed oil; HIGH S $=150 \mathrm{~g} \cdot \mathrm{kg}^{-1}$ wheat bran, sunflower oil; ${ }^{2} \mathrm{AME}_{\mathrm{N}}=$ metabolizable energy

Table 3. Most relevant fatty acids of the different diets administered in this study.

\begin{tabular}{|c|c|c|c|c|c|c|}
\hline \multirow{2}{*}{ Parameter $^{2}$} & \multicolumn{6}{|c|}{ Feed $^{1}$} \\
\hline & CON R & CON S & LOW R & LOW S & HIGH R & HIGH S \\
\hline Myristoleic acid (14:1) & 0.09 & 0.57 & 0.09 & 0.10 & 0.16 & 0.23 \\
\hline Palmitic acid (16:0) & 0.54 & 3.68 & 0.66 & 0.64 & 0.72 & 0.82 \\
\hline Palmitoleic acid (16:1) & 0.01 & $\mathrm{ND}$ & 0.01 & ND & 0.02 & 0.01 \\
\hline Stearic acid (18:0) & 0.10 & 1.15 & 0.12 & 0.19 & 0.14 & 0.28 \\
\hline Oleic acid (18:1) & 2.20 & 1.17 & 3.12 & 1.24 & 4.04 & 1.63 \\
\hline Linoleic acid (18:2) & 1.75 & 3.10 & 2.25 & 3.69 & 2.49 & 5.27 \\
\hline Linolenic acid (18:3) & 0.20 & 0.06 & 0.30 & 0.06 & 0.42 & 0.07 \\
\hline Eicosaenoic acid (20:1) & ND & ND & 0.03 & ND & 0.02 & ND \\
\hline$\Sigma S F A[g / 100 g]$ & 0.7 & 4.9 & 0.8 & 0.9 & 0.9 & 1.2 \\
\hline$\sum$ MUFA $[\mathrm{g} / 100 \mathrm{~g}]$ & 2.5 & 1.8 & 3.5 & 1.4 & 4.7 & 2.0 \\
\hline$\Sigma P U F A[g / 100 g]$ & 1.9 & 3.2 & 2.6 & 3.8 & 3.0 & 5.4 \\
\hline$\sum$ TUFA $[\mathrm{g} / 100 \mathrm{~g}]$ & 4.4 & 5.0 & 6.1 & 5.2 & 7.7 & 7.4 \\
\hline$\sum n-3$ PUFA [g/100g] & 0.2 & 0.1 & 0.3 & 0.1 & 0.4 & 0.1 \\
\hline$\sum n-6$ PUFA [g/100g] & 1.8 & 3.1 & 2.3 & 3.7 & 2.5 & 5.3 \\
\hline$\sum \mathrm{n}-6$ PUFA/ $\Sigma \mathrm{n}-3$ PUFA & 8.9 & 52.5 & 7.4 & 62.2 & 6.0 & 78.3 \\
\hline
\end{tabular}

${ }^{1} \mathrm{CON} \mathrm{R}=0 \mathrm{~g} \cdot \mathrm{kg}^{-1}$ wheat bran, rapeseed oil; CON S $=0 \mathrm{~g} \cdot \mathrm{kg}^{-1}$ wheat bran, sunflower oil; LOW R $=75$ $\mathrm{g} \cdot \mathrm{kg}^{-1}$ wheat bran, rapeseed oil; LOW S $=75 \mathrm{~g} \cdot \mathrm{kg}^{-1}$ wheat bran, sunflower oil; HIGH R $=150 \mathrm{~g} \cdot \mathrm{kg}^{-1}$ wheat bran, rapeseed oil; HIGH S $=150 \mathrm{~g} \cdot \mathrm{kg}^{-1}$ wheat bran, sunflower oil; ${ }^{2} \mathrm{SFA}=$ saturated fatty acids; MUFA = mono unsaturated fatty acids; PUFA = polyunsaturated fatty acids; ND = not detectable; TUFA $=$ total unsaturated fatty acids. 
the diets containing sunflower oil, whereas monounsaturated fatty acids (MUFA), and omega-3 polyunsaturated acids ( $\sum \mathrm{n}-3$ PUFA) showed lower concentrations. Regarding the $\alpha$-tocopherol, phosphorus and calcium concentrations in the diets, slight differences obviously were caused by analytical variability resulting from unavoidable small sample weights.

\subsection{Laying Performance Parameters and General Egg Quality}

As presented in Table 4 no differences were observed across the treatments regarding feed conversion ratio, live weight changes and egg mass. These results are in accordance with those of Ruan et al. [17]. Furthermore, no specific feed refusal due to the wheat bran containing diets was observed during the experiment, as daily feed intakes did not differ.

External and internal egg quality parameters are presented in Table 5. There were no differences across the different supplementations regarding egg weight, shell weight, albumen weight, yolk weight, haugh unit, shell thickness and eggshell breaking strength, regarding the dirtiness of the eggshells.

Diets comprising high amounts of fiber usually might increase fecal viscosity and cause watery and sticky excrements [18]. According to the present findings, neither the high nor the low WB level diet negatively influenced the cleanliness of the eggshells. On the contrary, in comparison with the control treatment, WB implementation rather led to cleaner eggshells. In fact, the control group showed 2.6 times more dirty eggshells compared to the HIGH treatment, while the LOW treatment displayed a factor of 1.6, respectively (data not shown). Hence, we assume that $150 \mathrm{~g} \cdot \mathrm{kg}^{-1} \mathrm{WB}$ in the diet did not alter the fecal viscosity and can be regarded as an appropriate proportion ensuring satisfactory egg surface quality, if NSP-hydrolyzing enzymes are included in the diet. This finding is of relevance in terms of consumer acceptance and marketability of the eggs.

Table 4. Variation of performance parameters as a result of different feeding regimes. Data represent least-squares-means and standard error of means (SEM) as well as significance levels of the influence of wheat bran (WB) and oil supplementation including their interaction $(\mathrm{WB} \times \mathrm{OIL})$.

\begin{tabular}{ccccccccccc}
\hline & \multicolumn{4}{c}{ Feed $^{1}$} & \multicolumn{5}{c}{ p-value } \\
\cline { 2 - 10 } & CON & LOW & HIGH & RSO & SFO & SEM & WB & OIL & WB $\times$ OIL \\
\hline $\begin{array}{c}\text { Daily feed intake [g/day] } \\
\text { Feed conversion }\end{array}$ & 105.6 & 107.4 & 106.7 & 107.8 & 105.3 & 1.035 & NS & NS & NS \\
$\begin{array}{c}\text { ratio [kg/kg] } \\
\text { Live weight changes [g] }\end{array}$ & 1.7 & 1.7 & 1.7 & 1.7 & 1.7 & 0.033 & NS & NS & NS \\
Egg mass [g] & 67.6 & 86.9 & 104.4 & 95.0 & 97.6 & 13.780 & NS & NS & NS \\
\hline
\end{tabular}

${ }^{1} \mathrm{CON}: 0 \mathrm{~g} \cdot \mathrm{kg}^{-1}$ wheat bran; LOW: $75 \mathrm{~g} \cdot \mathrm{kg}^{-1}$ wheat bran; HIGH: $150 \mathrm{~g} \cdot \mathrm{kg}^{-1}$ wheat bran; RSO: rapeseed oil; SFO: sunflower oil; ${ }^{2}=\mathrm{NS}$ : p-value $>0.1 ;^{*}=$ p-value $<0.1 ;{ }^{* *}=$ p-value $<0.05$; Identical superscripts represent no significant difference whereas differing letters indicate a significant distinction. $\mathrm{n}=24(6 \times 4)$; Egg mass: $\mathrm{n}=144(6 \times 4 \times 6)$. 
Table 5. Variation of internal and external egg quality parameters as a result of different hen feeding regimes. Data represent least-squares-means and standard error of means (SEM) as well as significance levels of the influence of wheat bran (WB) and oil supplementation including their interaction $(\mathrm{WB} \times \mathrm{OIL})$.

\begin{tabular}{|c|c|c|c|c|c|c|c|c|c|}
\hline \multirow{2}{*}{ Parameters $^{2}$} & \multicolumn{5}{|c|}{ Feed $^{1}$} & \multicolumn{4}{|c|}{ p-value } \\
\hline & $\mathrm{CON}$ & LOW & HIGH & RSO & SFO & SEM & WB & OIL & $\mathrm{WB} \times \mathrm{OIL}$ \\
\hline \multicolumn{10}{|l|}{ Egg } \\
\hline Shell breaking strength $[\mathrm{N}]$ & 5.8 & 6.3 & 6.0 & 6.2 & 5.9 & 0.343 & NS & NS & NS \\
\hline Haugh Units & 82.3 & 86.8 & 86.5 & 84.2 & 86.3 & 0.447 & NS & NS & NS \\
\hline Albumen weight [g] & 38.9 & 39.2 & 40.2 & 39.0 & 39.8 & 0.297 & NS & NS & NS \\
\hline Yolk weight $[\mathrm{g}]$ & 16.2 & 16.2 & 15.6 & 16.5 & 15.6 & 0.287 & NS & NS & NS \\
\hline Shell weight [g] & 6.6 & 6.5 & 6.7 & 6.6 & 6.6 & 0.061 & NS & NS & NS \\
\hline Shell thickness [mm] & 0.7 & 0.6 & 0.7 & 0.7 & 0.7 & 0.038 & NS & NS & NS \\
\hline \multicolumn{10}{|l|}{ Yolk } \\
\hline Luminance $\mathrm{L}^{*}$ & 53.1 & 52.9 & 52.2 & 53.1 & 52.3 & 0.704 & NS & NS & $* *$ \\
\hline Redness $a^{*}$ & $5.3^{\mathrm{a}}$ & $4.4^{\mathrm{b}}$ & $3.8^{\mathrm{c}}$ & 4.4 & 4.5 & 0.224 & $* *$ & NS & $* *$ \\
\hline Yellowness $b^{*}$ & $34.6^{\mathrm{a}}$ & $32.1^{\mathrm{b}}$ & $31.8^{\mathrm{b}}$ & 33.1 & 32.6 & 0.004 & * & NS & * \\
\hline $\mathrm{pH}$ & 6.0 & 6.0 & 6.2 & 6.1 & 6.0 & 0.032 & NS & NS & * \\
\hline Dry matter [\%] & 51.0 & 51.1 & 50.7 & 51.0 & 50.9 & 0.057 & NS & NS & NS \\
\hline Protein [\%] & 5.6 & 5.5 & 5.5 & 5.5 & 5.5 & 0.017 & NS & NS & NS \\
\hline Crude ash [\%] & 3.8 & 3.8 & 3.8 & 3.7 & 3.9 & 0.101 & NS & NS & * \\
\hline Crude fat [\%] & 55.9 & 56.0 & 56.7 & 55.6 & 56.9 & 0.057 & NS & NS & NS \\
\hline Cholesterol $[\mathrm{g} / 100 \mathrm{~g}]$ & 1.6 & 1.7 & 1.7 & 1.7 & 1.7 & 0.066 & NS & NS & NS \\
\hline$\alpha$-Tocopherol $[\mathrm{mg} / 100 \mathrm{~g}]$ & $150.8^{\mathrm{a}}$ & $189.4^{\mathrm{b}}$ & $227.5^{c}$ & $164.9^{\mathrm{a}}$ & $213.6^{\mathrm{b}}$ & 6.919 & $* *$ & ** & $* *$ \\
\hline
\end{tabular}

${ }^{1} \mathrm{CON}: 0 \mathrm{~g} \cdot \mathrm{kg}^{-1}$ wheat bran; LOW: $75 \mathrm{~g} \cdot \mathrm{kg}^{-1}$ wheat bran; HIGH: $150 \mathrm{~g} \cdot \mathrm{kg}^{-1}$ wheat bran; RSO: rapeseed oil; SFO: sunflower oil; ${ }^{2} \mathrm{NS}=\mathrm{p}$-value $>0.1 ;{ }^{*}=\mathrm{p}$-value $<0.1 ;{ }^{* *}=\mathrm{p}$-value $<0.05$; Identical superscripts represent no significant difference whereas differing letters indicate a significant distinction. Egg: $\mathrm{n}=144$ (6 $\times 4 \times 6)$; Yolk: $\mathrm{n}=48(6 \times 4 \times 2)$.

\subsection{Yolk Quality}

Across the different diets, no differences were observed regarding $\mathrm{pH}$-value, dry matter, protein and fat contents as well as lightness $L^{*}$. As presented in Table 5, increasing WB contents in the diet correlated with decreased yolk redness and yolk yellowness.

The diverse egg quality parameters examined in this study suggest that both a $75 \mathrm{~g} \cdot \mathrm{kg}^{-1}$ and a $150 \mathrm{~g} \cdot \mathrm{kg}^{-1}$ of WB proportion in the diet are appropriate, as no adverse effects on egg quality were observed. These findings are in agreement with those of Ruan et al. [18], who did not report any negative impact of diets containing $180 \mathrm{~g} \cdot \mathrm{kg}^{-1}$ rice bran on duck egg quality and yolk color. Likewise, Incharoen and Maneechote [19] found that $30 \mathrm{~g} \cdot \mathrm{kg}^{-1}$ and $60 \mathrm{~g} \cdot \mathrm{kg}^{-1}$ of whole rice hulls resulted in acceptable egg quality, but in decreased yellowness of the yolk. 
It is well known that corn provides high amounts of xanthophylls, which are responsible for the yellow color of the yolk. Hence, theoretically and also supported by the present data, corn substitution by WB usually results in a reduced level of xanthophylls and thus in lower color intensity.

The two oil sources used did not influence the yolk color. This finding is in contrast to that of Ceylan et al. [5], who observed a decrease in yolk color intensity, when sunflower oil was applied in comparison to rapeseed oil. Dalle Zotte et al. [20] claimed that yolk color can be modulated by the addition of various oils, mainly based on the natural pigments (e.g., oxicarotenoid in linseed oil). In this context, it should be stressed that different methods for measuring the yolk color may yield different results. For example, Ceylan et al. [5] used a Roche Yolk Color Fan for determining the yolk color, while in our study yolk color was assessed by means of reflectance colorimetry. Having some impact on the marketability of the eggs, we conclude that neither WB supplementation nor the two different oils used exert negative effects on yolk color.

\subsubsection{Cholesterol}

Among the different feeding regimes, no differences were evident regarding the cholesterol levels. Although earlier findings [21] indicated decreased cholesterol levels in egg yolk content resulting from a diet with a low $\sum n-6$ PUFA/ $\sum n-3$ PUFA ratio, results elaborated in our study did not indicate such an effect on egg yolk cholesterol concentration. Considering other studies hitherto undertaken, contradictory findings become evident: Dalle Zotte et al. [20] observed increased yolk cholesterol contents as a result of a diet supplemented with linseed (low $\sum$ n-6 PUFA/ $\sum$ n-3 PUFA ratio). Our data yet are concordant with those of other authors [5] [22], who reported no correlation of $\sum n-3$ PUFA content in laying hens' feed and cholesterol content of corresponding eggs. Ceylan et al. [5] did not observe any differences in the cholesterol content of the yolks, when laying hens were fed with diets containing sunflower, fish, linseed or rapeseed oil at levels up to $3 \%$. Based on our findings we do not support the hypothesis that the fatty acid profile influences the cholesterol level of the yolk. We rather assume that the cholesterol content found in the yolk is not directly correlated with the $\Sigma \mathrm{n}-3$ PUFA content in the feed. This may be a result of some physiological reasons: certain cholesterol contents are indispensable for the development of the embryo and can therefore not be reduced by feeding strategies [5].

\subsubsection{Fatty Acid Profiles}

Table 6 shows the effect of the dietary supplementation with $\mathrm{WB}$, rapeseed oil and sunflower oil on the fatty acid profile of the yolks. The fatty acid profile in the yolk was generally proportional to the fatty acid pattern of the dietary supplementation and hence reflected that of the laying hens' diets. However, the diet, neither WB nor the oil supplementation, did not influence C17:1, C20:3n-6 and C22:5n-3 levels. This is consistent with the study of Celebi and Macit [23]. Authors fed laying hens with $1 \%$ and $2 \%$ tallow, flaxseed or sunflower oil, and 
Table 6. Most relevant fatty acids in the yolk as a result of different hen feeding regimes. Data represent least-squares-means and standard error of means (SEM) as well as significance levels of the influence of wheat bran (WB) and oil supplementation including their interaction $(\mathrm{WB} \times \mathrm{OIL})$.

\begin{tabular}{|c|c|c|c|c|c|c|c|c|c|}
\hline \multirow{2}{*}{ Fatty acids $(g / 100 g)^{2}$} & \multicolumn{5}{|c|}{ Treatments $^{1}$} & \multicolumn{4}{|c|}{ p-value } \\
\hline & $\mathrm{CON}$ & LOW & $\mathrm{HIGH}$ & RSO & SFO & SEM & WB & OIL & $\mathrm{WB} \times \mathrm{OIL}$ \\
\hline Myristic acid (14:0) & $0.18^{\mathrm{a}}$ & $0.15^{\mathrm{b}}$ & $0.13^{\mathrm{c}}$ & 0.15 & 0.16 & 0.004 & $* *$ & NS & NS \\
\hline Palmitic acid (16.0) & $15.02^{\mathrm{a}}$ & $13.65^{\mathrm{ab}}$ & $13.53^{\mathrm{b}}$ & $13.47^{\mathrm{b}}$ & $14.67^{\mathrm{a}}$ & 0.249 & * & * & NS \\
\hline Palmitoleic acid (16:1) & $1.44^{\mathrm{a}}$ & $0.10^{\mathrm{c}}$ & $0.86^{\mathrm{b}}$ & $1.22^{\mathrm{a}}$ & $1.01^{\mathrm{b}}$ & 0.047 & $* *$ & $* *$ & $* *$ \\
\hline Heptadecaenoic acid $(17: 1)$ & 0.03 & 0.03 & 0.02 & 0.03 & 0.02 & 0.002 & NS & NS & NS \\
\hline Stearic acid (18:0) & 3.96 & 3.76 & 4.11 & $3.50^{\mathrm{a}}$ & $1.38^{\mathrm{b}}$ & 0.139 & NS & $* *$ & NS \\
\hline Oleic acid (18:1) & 21.80 & 21.55 & 21.47 & $24.92^{\mathrm{a}}$ & $18.30^{\mathrm{b}}$ & 0.597 & NS & $* *$ & ** \\
\hline Linoleic acid (18:2) & $9.88^{\mathrm{b}}$ & $11.71^{\mathrm{a}}$ & $12.88^{\mathrm{a}}$ & $8.05^{\mathrm{b}}$ & $14.93^{\mathrm{a}}$ & 0.573 & ** & $* *$ & ** \\
\hline $\begin{array}{c}\text { Eicosadienoic acid } \\
\quad(20: 2 n-6)\end{array}$ & $0.08^{\mathrm{b}}$ & $0.11^{\mathrm{a}}$ & $0.13^{\mathrm{a}}$ & $0.07^{\mathrm{b}}$ & $0.14^{\mathrm{a}}$ & 0.007 & ** & ** & $* *$ \\
\hline $\begin{array}{c}\text { Eiconsatrienoic acid } \\
\qquad(20: 3 n-6)\end{array}$ & 0.06 & 0.04 & 0.04 & 0.04 & 0.05 & 0.005 & NS & NS & NS \\
\hline Arachidonic acid (20:4n-6) & 0.94 & 0.90 & 0.92 & $0.83^{\mathrm{b}}$ & $1.02^{\mathrm{a}}$ & 0.022 & NS & $* *$ & NS \\
\hline $\begin{array}{l}\text { Docosapentaenoic } \\
\text { acid }(22: 5 n-3)\end{array}$ & 0.03 & 0.08 & 0.04 & 0.07 & 0.03 & 0.013 & NS & NS & NS \\
\hline $\begin{array}{l}\text { Docosahexaenoic } \\
\text { acid }(22: 6 n-3)\end{array}$ & 0.24 & 0.25 & 0.26 & $0.38^{\mathrm{a}}$ & $0.12^{\mathrm{b}}$ & 0.024 & NS & ** & NS \\
\hline$\Sigma$ SFA & 18.87 & 18.14 & 17.55 & $17.37^{\mathrm{a}}$ & $19.01^{\mathrm{b}}$ & 0.267 & NS & $* *$ & NS \\
\hline$\sum$ MUFA & 22.78 & 22.67 & 22.43 & $26.06^{\mathrm{a}}$ & $19.20^{\mathrm{b}}$ & 0.632 & NS & $* *$ & $* *$ \\
\hline$\sum$ PUFA & $11.36^{\mathrm{c}}$ & $13.40^{\mathrm{b}}$ & $14.60^{\mathrm{a}}$ & $9.77^{\mathrm{b}}$ & $16.47^{\mathrm{a}}$ & 0.591 & $* *$ & $* *$ & ** \\
\hline$\Sigma$ TUFA & 35.03 & 36.25 & 37.17 & 36.24 & 36.06 & 0.533 & NS & NS & NS \\
\hline$\sum$ n-6 PUFA & $10.82^{c}$ & $12.67^{\mathrm{b}}$ & $14.05^{\mathrm{a}}$ & $8.93^{\mathrm{b}}$ & $16.09^{\mathrm{a}}$ & 0.612 & $* *$ & $* *$ & $* *$ \\
\hline$\sum$ n-3 PUFA & $0.48^{\mathrm{b}}$ & $0.62^{\mathrm{a}}$ & $0.61^{\mathrm{a}}$ & $0.91^{\mathrm{a}}$ & $0.23^{\mathrm{b}}$ & 0.057 & $* *$ & $* *$ & $* *$ \\
\hline$\sum n-6$ PUFA/ $\Sigma \mathrm{n}-3$ PUFA & 32.90 & 44.72 & 45.31 & $10.06^{\mathrm{b}}$ & $71.89^{\mathrm{a}}$ & 5.171 & NS & $* *$ & ** \\
\hline
\end{tabular}

${ }^{1} \mathrm{CON}=0 \mathrm{~g} \cdot \mathrm{kg}^{-1}$ wheat bran; LOW: $75 \mathrm{~g} \cdot \mathrm{kg}^{-1}$ wheat bran; HIGH: $150 \mathrm{~g} \cdot \mathrm{kg}^{-1}$ wheat bran; RSO: rapeseed oil; SFO: sunflower oil; SFA = saturated fatty acids; MUFA = mono unsaturated fatty acids; PUFA = polyunsaturated fatty acids; TUFA $=$ total unsaturated fatty acids. ${ }^{2} \mathrm{NS}=\mathrm{p}$-value $>0.1{ }^{*}=\mathrm{p}$-value $<0.1 ;{ }^{* *}=\mathrm{p}$-value $<0.05$; Identical superscripts represent no significant difference whereas differing letters indicate a significant distinction. $\mathrm{n}=48(6 \times 4 \times 2)$.

resulting egg yolks showed no differences in $\mathrm{C} 17: 1$ and $\mathrm{C} 20: 3$. We presume that these findings are closely related to the low levels of these fatty acids in the diets. Wheat bran and vegetable oil supplementation did not affect the SFA, MUFA and the ratio of $\sum \mathrm{n}-6$ PUFA $/ \Sigma \mathrm{n}-3$ PUFA, but $15 \%$ WB increased the total amount of PUFA (+28.5\%), n-6 PUFA (+29.9\%) and n-3 PUFA (+27.1\%). Additionally, 15\% WB increased linoleic acid by $30.4 \%$ and eicosanoic acid by $62.5 \%$ and decreased myristic acid by $27.8 \%$, palmitic acid by $9.9 \%$ and palmitoleic acid by $40.3 \%$. These compositional shifts are the result of the diverging 
fatty acid contents in the two feed compounds WB and corn. Compared to corn ( $0.2 \% \sum \mathrm{n}-3$ PUFA and $62.2 \% \sum \mathrm{n}-6$ PUFA of total fat) WB provides proportions of $1.2 \% \sum n-3$ PUFA and $59.7 \% \sum n-6$ PUFA of total fat [24]. Interestingly, even though the source of PUFA and $\sum \mathrm{n}-6$ PUFA is more or less at the same level in both crops, the present findings indicate some increased concentration of $\sum \mathrm{n}-6$ PUFA in the yolk when WB and vegetable oil were supplemented. Although we did not discover any information in the literature explaining this phenomenon, it is likely that the higher levels of oils in the diets comprising WB are responsible for this compositional shift. This assumption is further supported by the findings of Ceylan et al. [5], who reported an increase in PUFA as a result of higher inclusion levels of fat. Among this, according to the literature and also supported by the present study it is well known that the transformation of MUFA in the feed to the egg yolk is limited [25]. These facts may be of major relevance for the observed shifts in the fatty acid profile of the yolks.

As a matter of fact, oil supplementation to the feed is the most significant factor influencing the fatty acid composition of the yolk. Expectedly, SFA (+9.4\%), PUFA (+68.6\%), $\sum \mathrm{n}-6$ PUFA (+80.2\%) levels as well as the ratio of $\sum \mathrm{n}-6$ PUFA/ $\Sigma \mathrm{n}-3$ PUFA ( $+614.6 \%)$ increased as a result of the addition of sunflower oil, while the concentration of MUFA (-26.3\%) and n-3 PUFA (-74.7\%) decreased.

The addition of sunflower oil led to an increased concentration of palmitic acid (+8.9\%), linoleic acid (+85.5\%), eicosadienoic acid $(+100.0 \%)$ and arachidonic acid $(+22.9 \%)$, but to decreased palmitoleic acid $(-17.2 \%)$, stearic acid $(-60.6 \%)$, oleic acid $(-26.6 \%)$ and DHA $(-68.4 \%)$ levels. Compared with rapeseed oil the contents of palmitoleic acid, stearic acid and oleic acid in sunflower oil are hardly pronounced. The level of linoleic acid in sunflower oil is $47.4 \%$ whereas rapeseed oil comprises approximately $28.1 \%$ [5]. According to the literature [5] [25] and also supported by the present study, increasing levels of linoleic acid in the diet-derived from different oil sources-result in increased linoleic acid levels in the yolk.

Interestingly, eicosapentaenoic acid (EPA) was not detected in any yolk regardless of the diet applied. This is in agreement with the study of Celebi and Macit [23], who also did not find EPA in yolks of laying hens fed with either tallow or sunflower oil. Although linolenic acid-usually converted to EPA-was abundant in all diets, administered in our study, EPA did not appear in any yolk. However, docosapentaenoic acid (DPA) and docosahexaenoic acid (DHA) were efficiently transformed from precursors in the feed into the yolk. Similar effects were observed by Baucells et al. [25], who observed a remarkable higher DHA levels in yolks derived from laying hens fed a diet with low DHA and high EPA levels. Hence, we assume that, EPA was transformed via diverse enzymatic systems to DHA even before the deposition in the yolk took place.

Among other oils, rapeseed is well known as an efficient source of $\sum n-3$ PUFA, also providing a nutritionally ideal $\sum n-6$ PUFA/ $\sum n-3$ PUFA ratio of approximately four. On the contrary, sunflower oil possesses a rather unfavorable 
ratio of $\sum n-6$ PUFA/ $\sum n-3$ PUFA of approximately 260 [5] [24]. It is well known that $\sum \mathrm{n}-6$ PUFA and $\sum \mathrm{n}-3$ PUFA can be partially converted to EPA and DHA, and therefore enhance the nutritional quality of the yolk [20]. Laying hens own a well-developed enzymatic system to incorporate long-chain $\sum n-3$ PUFA in the yolk by converting it from alpha-linolenic acid $(\mathrm{C} 18: 3 n-3)$ provided by their feed. Thus egg yolk can be enriched with oils rich in long-chain $\sum n-3$ PUFA, mostly DHA by supplementing the feed with long-chain $\sum \mathrm{n}-3$ PUFA [7]. From the viewpoint of human nutrition, a $\sum \mathrm{n}-6$ PUFA/ $\sum \mathrm{n}-3$ PUFA ratio lower than 5:1 is recommended for human diets [20]. Egg yolks from free-ranging chicken usually exhibit a $\sum \mathrm{n}-6$ PUFA/ $\sum \mathrm{n}-3$ PUFA ratio of 1.3:1 [26], whereas egg yolks from laying hens provided with a common diet display a ratio of approximately 11.4:1 [20]. In the present study, laying hens receiving a diet containing 150 $\mathrm{g} \cdot \mathrm{kg}^{-1} \mathrm{WB}$ and $62 \mathrm{~g} \cdot \mathrm{kg}^{-1}$ rapeseed oil produced egg yolks with a more favorable $\sum$ n-6 PUFA/ $\sum$ n-3 PUFA ratio of 9:1, whereas those eggs collected from hens fed with the control diet containing rapeseed oil showed a ratio of 12:1.

Interestingly, our observations did not confirm the findings of Ceylan et al. [5], who either fed $15 \mathrm{~g} \cdot \mathrm{kg}^{-1}$ or $3 \mathrm{~g} \cdot \mathrm{kg}^{-1}$ rapeseed or sunflower oil but did not detect any differences regarding the $\Sigma \mathrm{n}-6$ PUFA levels in the yolk. We therefore, assume that the effect observed in our study might be a result of relatively higher supplementation levels of oil $\left(29 \mathrm{~g} \cdot \mathrm{kg}^{-1}-62 \mathrm{~g} \cdot \mathrm{kg}^{-1}\right)$. Thus in general, a feeding regime consisting of $\mathrm{WB}$ and rapeseed oil can be recommended for egg production with a favorable nutritional value.

\subsubsection{Tocopherol}

Sunflower oil addition caused a marked increase $(+29.5 \%)$ in the $\alpha$-tocopherol level of the yolk. Likewise, the addition of WB also resulted in increased $\alpha$-tocopherol concentrations (CON vs. LOW: $+25.6 \%$; CON vs. HIGH: $+25.8 \%$ ).

After resorption in the laying hens' intestinal tract, dietary $\alpha$-tocopherol is usually distributed in the body via metabolic pathways. The major proportion is accumulated in the fatty tissue of the hens, in the liver including gallbladder, kidney, brain, thigh, and breast, but remarkable concentrations are further embedded in the yolk [27]. Accordingly, Alizadeh et al. [21] recommended hen feeding with diets high in tocopherol in order to obtain yolks rich in tocopherol. However, the same authors disadvantageously reported a higher susceptibility of 乏n-3 PUFA to lipid peroxidation, which in turn might increase vitamin requirements for the metabolism of the birds. In the present study we did not observe a correlation of $\Sigma \mathrm{n}-6$ PUFA/ $\Sigma \mathrm{n}-3$ PUFA ratio and $\alpha$-tocopherol content, but with decreasing amounts of vitamin $E$ also the amount of $\sum n-6$ PUFA decreased in the yolk. Thus, we suggest that laying hens fed with a diet high in $\alpha$-tocopherol (e.g., containing WB as a natural source) produce egg yolk qualities with higher $\alpha$-tocopherol levels concentration. Hence, a feed high in natural $\sum$ n-3 PUFA and $\alpha$-tocopherol yields yolks rich in $\alpha$-tocopherol and further exhibits a nutritionally beneficial low $\sum \mathrm{n}-6$ PUFA/ $\Sigma \mathrm{n}-3$ PUFA ratio. 


\subsection{Microbiological Criteria}

No Salmonella contaminations were detected in the eggs as well as in the faeces throughout the experiments. We assume that this was due to the good hygiene quality of the feed. Moreover, there is some evidence, that a diet high in fiber may promote some enhanced resilience against Salmonella infections [28].

\section{Conclusions}

Results obtained indicate that increasing dietary fiber levels supplemented to the diet for laying hens exert no adverse effects regarding the performance of laying hens, as well as the chemical, physical and microbiological egg quality parameters. Moreover, increasing WB and vegetable oil contents in the diet correlate with an ameliorated $\alpha$-tocopherol concentration, increased PUFA, $\Sigma \mathrm{n}-3$ PUFA, and $\sum \mathrm{n}-6$ PUFA levels and a favorable $\sum \mathrm{n}-6$ PUFA $/ \Sigma \mathrm{n}-3$ PUFA ratio in the eggs, especially when rapeseed oil is added in order to intentionally balance the energy level of the feed. As a result of this effect, the nutritive value of eggs produced under given conditions can be enhanced. Regardless of high dietary fiber content in the feedstuffs, laying hens tolerate higher fiber levels. Therefore, WB supplementation can be regarded as an interesting option for a sustainable utilization of low-cost feed supplements originating from by-products of the food industry.

\section{Acknowledgements}

We gratefully acknowledge the Good Mills Group GmbH, Austria, for their support.

\section{References}

[1] Wanzenböck, E., Apprich, S., Tirpanalan, Ö., Zitz, U., Kracher, D., Schedle, K. and Kneifel, W. (2017) Wheat Bran Biodegradation by Edible Pleurotus Fungi-A Sustainable Perspective for Food and Feed. LWT-Food Science and Technology, 86, 123-131. https://doi.org/10.1016/j.lwt.2017.07.051

[2] Schedle, K. (2016) Sustainable Pig and Poultry Nutrition by Improvement of Nutrient Utilisation-A Review. Die Bodenkultur. Journal of Land Management, Food and Environment, 67, 45-60. https://doi.org/10.1515/boku-2016-0005

[3] Stevenson, L., Phillips, F., O’Sullivan, K. and Walton, J. (2012) Wheat Bran: Its Composition and Benefits to Health, a European Perspective. International Journal of Food Sciences and Nutrition, 63, 1001-1013. https://doi.org/10.3109/09637486.2012.687366

[4] Mansoori, B., Modirsanei, M. and Kiaei, M.M. (2006) Cumin Seed Meal as an Alternative to Wheat Bran in Commercial Laying Hen Diets. Journal of the Science of Food and Agriculture, 86, 2134-2139. https://doi.org/10.1002/jsfa.2587

[5] Ceylan, N., Ciftci, I., Mizrak, C., Kahraman, Z. and Efil, H. (2011) Influence of Different Dietary Oil Sources on Performance and Fatty Acid Profile of Egg Yolk in Laying Hens. Journal of Animal and Feed Sciences, 20, 71-83.

[6] Schreiner, M., Meraji, S. and Moreira, R. (2005) Omega-3 Enriched Eggs: Positional 
Distribution of Fatty Acids in Response to Different Dietary Lipids. Lipid Technology, 17, 271-275.

[7] Schreiner, M., Moreira, R.G. and Hulan, H.W. (2006) Positional Distribution of Fatty Acids in Egg Yolk Lipids. Journal of Food Lipids, 13, 36-56. https://doi.org/10.1111/j.1745-4522.2006.00033.x

[8] Moradi, S., Zaghari, M., Shivazad, M., Osfoori, R. and Mardi, M. (2013) Response of Female Broiler Breeders to Qualitative Feed Restriction with Inclusion of Soluble and Insoluble Fiber Sources. Journal of Applied Poultry Research, 22, 370-381. https://doi.org/10.3382/japr.2012-00504

[9] Grizard, D. and Barthomeuf, C. (1999) Non-Digestible Oligosaccharides Used as Prebiotic Agents: Mode of Production and Beneficial Effects on Animal and Human Health. Reproduction Nutrition Development, 39, 563-588. https://doi.org/10.3382/japr.2012-00504

[10] FAO (2010) World Livestock-Livestock in Food Security. Rome, Italy.

[11] Eisen, E.J., Bohren, B.B. and McKean, H.E. (1962) The Haugh Unit as a Measure of Egg Albumen Quality. Poultry Science, 41, 1461-1468. https://doi.org/10.3382/ps.0411461

[12] Naumann, C. and Bassler, R. (2012) Die chemische Untersuchung von Futtermitteln. VDLUFA-Verlag, Darmstadt.

[13] Makkar, H.P.S., Siddhuraju, P. and Becker, K. (2007) Phytic Acid. In: Walker, J.M., Ed., Molecular Biology: Plant Secondary Metabolites, Humana Press, Totowa, 23-27. https://doi.org/10.1007/978-1-59745-425-4_5

[14] Schreiner, M. (2006) Optimization of Solvent Extraction and Direct Transmethylation Methods for the Analysis of Egg Yolk Lipids. International Journal of Food Properties, 9, 573-581. https://doi.org/10.1080/10942910600596290

[15] Panfili, G., Fratianni, A. and Irano, M. (2003) Normal Phase High-Performance Liquid Chromatography Method for the Determination of Tocopherols and Tocotrienols in Cereals. Journal of Agricultural and Food Chemistry, 51, 3940-3944. https://doi.org/10.1021/jf030009v

[16] Musgrove, M.T., Jones, D.R., Northcutt, J.K., Cox, N.A. and Harrison, M.A. (2005) Shell Rinse and Shell Crush Methods for the Recovery of Aerobic Microorganisms and Enterobacteriaceae from Shell Eggs. Journal of Food Protection, 68, 2144-2148. https://doi.org/10.4315/0362-028X-68.10.2144

[17] Ruan, D., Lin, Y.C., Chen, W., Wang, S., Xia, W.G., Fouad, A.M. and Zheng, C.T. (2015) Effects of Rice Bran on Performance, Egg Quality, Oxidative Status, Yolk Fatty Acid Composition, and Fatty Acid Metabolism-Related Gene Expression in Laying Ducks. Poultry Science, 94, 2944-2951. https://doi.org/10.4315/0362-028X-68.10.2144

[18] Ahmadi, F. and Rahimi, F. (2011) Factors Affecting Quality and Quantity of Egg Production in Laying Hens: A Review. World Applied Sciences Journal, 12, 372-384.

[19] Incharoen, T. and Maneechote, P. (2013) The Effects of Dietary Whole Rice Hull as Insoluble Fiber on the Flock Uniformity of Pullets and on the Egg Performance and Intestinal Mucosa of Laying Hens. American Journal of Agricultural and Biological Sciences, 8, 323-329. https://doi.org/10.3844/ajabssp.2013.323.329

[20] DalleZotte, A., Andrighetto, I., Giaccone, V. and Marchesini, G. (2015) Dietary Enrichment of N-3 PUFA for Laying Hens: Effect of Different Sources on Production, Composition and Quality of Eggs. Animal Science Papers and Reports, 33, 
411-424.

[21] Alizadeh, M.R., Mahdavi, A.H., Rahmani, H.R. and Jahanian, E. (2015) Effects of Different Levels of Clove Bud (Syzygium aromaticum) on Yolk Biochemical Parameters and Fatty Acids Profile, Yolk Oxidative Stability, and Ovarian Follicle Numbers of Laying Hens Receiving Different N-6 to N-3 Ratios. Animal Feed Science and Technology, 206, 67-75.

https://doi.org/10.1016/j.anifeedsci.2015.05.007

[22] Ayerza, R. and Coates, W. (2001) Omega-3 Enriched Eggs: The Influence of Dietary $\alpha$-Linolenic Fatty Acid Source on Egg Production and Composition. Canadian Journal of Animal Sciences, 81, 355-362. https://doi.org/10.4141/A00-094

[23] Celebi, S. and Macit, M. (2008) The Effects of Sources of Supplemental Fat on Performance, Egg Quality, and Fatty Acid Composition of Egg Yolk in Laying Hens. Journal of the Science of Food and Agriculture, 88, 2382-2387.

https://doi.org/10.1002/jsfa.3360

[24] Orsavova, J., Misurcova, L., Ambrozova, J.V., Vicha, R. and Mlcek, J. (2015) Fatty Acids Composition of Vegetable Oils and Its Contribution to Dietary Energy Intake and Dependence of Cardiovascular Mortality on Dietary Intake of Fatty Acids. International Journal of Molecular Sciences, 16, 12871-12890. https://doi.org/10.3390/ijms160612871

[25] Baucells, M.D., Crespo, N., Barroeta, A.C., López-Ferrer, S. and Grashorn, M.A. (2009) Incorporation of Different Polyunsaturated Fatty Acids into Eggs. Poultry Science, 79, 51-59. https://doi.org/10.1093/ps/79.1.51

[26] Simopoulos, A.P. (2016) An Increase in the Omega-6/Omega-3 Fatty Acid Ratio Increases the Risk for Obesity. Nutrients, 8, 128. https://doi.org/10.3390/nu8030128

[27] Hansen, H., Wang, T., Dolde, D. and Xin, H. (2015) Tocopherol and Annatto Tocotrienols Distribution in Laying-Hen Body. Poultry Science, 94, 2421-2433. https://doi.org/10.3382/ps/pev228

[28] Vermeulen, K., Verspreet, J., Courtin, C.M., Haesebrouck, F., Ducatelle, R. and Van Immerseel, F. (2017) Reduced Particle Size Wheat Bran Is Butyrogenic and Lowers Salmonella Colonization, When Added to Poultry Feed. Veterinary Microbiology, 198, 64-71. https://doi.org/10.1016/j.vetmic.2016.12.009 